\title{
Assessment of the value of the different variants of abnormal digital rectal examination finding in predicting carcinoma of the prostate: a preliminary report of a two-center study
}

\author{
Eshiobo Irekpita ${ }^{*}$, George Okwudili Achor ${ }^{2}$ and Ugochukwu Alili ${ }^{3}$
}

\begin{abstract}
Background: Digital rectal examination is a veritable tool for the clinical diagnosis and screening for carcinoma of the prostate. This study aims to assess the value of the different variables which constitute abnormal digital rectal examination (DRE) findings.

Results: Following ethical approval, one hundred and thirty-one men met the inclusion criteria and were enrolled in the study. The peak incidence of abnormal DRE finding was in the 8th decade of life, while the PPV was $66.5 \%$. Of the total, 44 (33.5\%) were nodular hyperplasia, 12 (9.2\%) were prostate intra-epithelia neoplasia, while 75 (57.3\%) were adenocarcinoma. With a positive predictive value (PPV) of 73.3\%, a hard nodular feel was the only abnormal DRE finding that independently and significantly predicted the risk of prostatic adenocarcinoma. A suspicious nodule and obliterated median groove had PPV of $23.1 \%$ and lobar asymmetry, $0 \%$. There was a statistically significant correlation $(P=0.005)$ between DRE findings and histology, between PSA and histology $(P=0.000)$ and between the size of the prostate and PSA value $(P=0.021)$. The mean size of the prostate was $101.2 \mathrm{~g}$, standard deviation 92.11783 , maximum $648 \mathrm{~g}$ and minimum $13.6 \mathrm{~g}$.

Conclusion: Most of the variants of abnormal DRE findings do not sufficiently predict the risk of adenocarcinoma on their own. They need to be in combination with other DRE findings or a raised PSA to significantly predict adenocarcinoma.
\end{abstract}

Keywords: Digital rectal examination, Variants of abnormal DRE finding, Positive predictive value, Adenocarcinoma of the prostate

\section{Background}

Carcinoma of the prostate continues to be a major health burden worldwide with a life time prevalence of $17 \%$. Diseases of the prostate are extremely common among aging men, to the extent that some have suggested that this condition is a natural concomitant of aging [1]. In $2007,218,809$ diagnoses of the disease were expected to be made in the USA with corresponding deaths of 27,050

\footnotetext{
*Correspondence: ieshiobo@yahoo.com

${ }^{1}$ Department of Surgery, Ambrose Alli University, Ekpoma, Nigeria Full list of author information is available at the end of the article
}

[2]. It has been documented to be the most common malignancy in men, accounting for more than 27,000 new cancer cases in the UK in 2000 and nearly 9900 deaths in 2002 [3]. Such data are not readily available in Nigeria and most other Sub Saharan African countries.

The hallmark of clinical examination of a patient with the disease is the digital rectal examination (DRE). Digital rectal examination is the oldest, least invasive screening tool for prostate cancer with a high specificity and a high negative predictive value though its moderate sensitivity does not allow for conclusions [4]. Variables that constitute abnormal digital rectal examination findings 
are enlargement of the prostate, presence of suspicious nodule(s), lobar asymmetry, a hard consistency, obliteration of the median groove, induration of a lobe or the whole prostate and palpable seminal vesicles. Prostate biopsy is recommended when DRE findings are abnormal except in the first mentioned variable which requires additional information such as PSA. Findings such as fixity to the rectum and obliteration of the lateral sulci are considered as features of advanced disease.

Prostate-specific antigen (PSA) replaced acid phosphatase in 1986 as an investigative modality though it is neither specific nor sensitive as it is normal in some patients with histologically proven disease and elevated in benign lesions such as prostatitis. The upper limit of normal for PSA is $4 \mathrm{ng} / \mathrm{ml}$ above which prostate biopsy is recommended though there is evidence that at this level, some cancers are missed. This upper limit of normal of PSA is, however, age related. PSA is presently the most reliable tumor marker for carcinoma of the prostate with a higher predictive value than DRE [5]. A combination of DRE and PSA evaluation is recommended as screening tools for carcinoma of the prostate. However, instances abound where the PSA is normal and a positive histology is obtained based on an abnormal DRE finding. DRE is therefore an essential part of the assessment that can independently predict prostate cancer in the setting of a normal PSA level [6]. The standard approach to the diagnoses of prostate cancer consists of prostate-specific antigen (PSA), digital rectal examination (DRE) and transrectal biopsy. This triad has been documented as incapable of detecting all prostate cancers. It has been found to incorrectly grade some of them and also detect a significant number of indolent and latent diseases, raising the fear of over diagnosis and overtreatment [7].

This study aims at assessing these variables which constitute abnormal digital rectal examination finding as indication for biopsy in men with suspected carcinoma of the prostate in Nigeria.

\section{Method}

This is a prospective, cross-sectional, hospital-based, two-center study. It took place between April 2016 and June 2017. Following Ethical approval, all men who presented at the urology outpatient and the accident and emergency unit of the hospitals with LUTS BPH and an abnormal DRE findings within the study period and who consented to the study were included. However, those who were on treatment before referral to the units or who had prostate biopsy based solely on a raised PSA were excluded. The sample size was determined using a population estimate of 350,000 adult men based in Edo central, a confidence interval of 95 and error margin of 5 .
Digitally guided transrectal biopsy of the prostate was done based on abnormal DRE finding alone though a blood sample for PSA was collected before the biopsy. A sextant biopsy and 3-4 targeted biopsies were obtained under surface anesthesia or caudal block in each patient. The sextant biopsies were taken from the base, middle and apical areas of the prostate. The targeted biopsies were directed at the suspicious area(s) and in the case of obliterated median groove, the midline. The prostate size was determined by trans-abdominal ultrasonography.

DRE was done by a specialist urologist in the participating centers just before the biopsy. All the patients had antibiotic prophylaxis according to the center's policy. The specimen was preserved in $10 \%$ formalin and sent to the histopathology laboratory. Histopathology report was categorized as nodular hyperplasia, prostate intra-epithelial neoplasia and adenocarcinoma. The Gleason's scoring system was used to further categorize the adenocarcinomas into well differentiated, moderately well differentiated and anaplastic.

Data related to age, type of abnormal DRE finding(s), PSA value and histopathology report of each patient were assembled in a proforma designed for the study. The different variants of abnormal DRE findings were assessed and compared with the pathology report of biopsy specimen. The data so obtained were analyzed using simple statistical methods and the SPSS version 21. $P$ value of 0.05 and below was taken as statistically significant.

\section{Results}

Following ethical approval, a total of 131 men who met the inclusion criteria were selected. Table 1 shows the age distribution of the men in decades.

Of the total, 44 (33.5\%) were nodular hyperplasia, 12 (9.2\%) were prostate intra-epithelia neoplasia (PIN), while $75(57.3 \%)$ were adenocarcinoma giving a positive predictive value (PPV) of $66.5 \%$ for malignancy (Fig. 1). A total of 75 participants had their Gleason score available out of which 25 (33.3\%) were anaplastic, 48 (64\%) were moderately well differentiated, while $2(2.7 \%)$ were well differentiated.

Table 1 Age distribution in decades

\begin{tabular}{lcccc}
\hline Decade & Frequency & Percent & Valid percent & $\begin{array}{c}\text { Cumulative } \\
\text { percent }\end{array}$ \\
\hline 51-60 & 18 & 13.7 & 13.7 & 13.7 \\
61-70 & 42 & 32.1 & 32.1 & 45.8 \\
71-80 & 46 & 35.1 & 35.1 & 80.9 \\
Above 80 & 25 & 19.1 & 19.1 & 100.0 \\
Total & 131 & 100.0 & 100.0 & \\
\hline
\end{tabular}




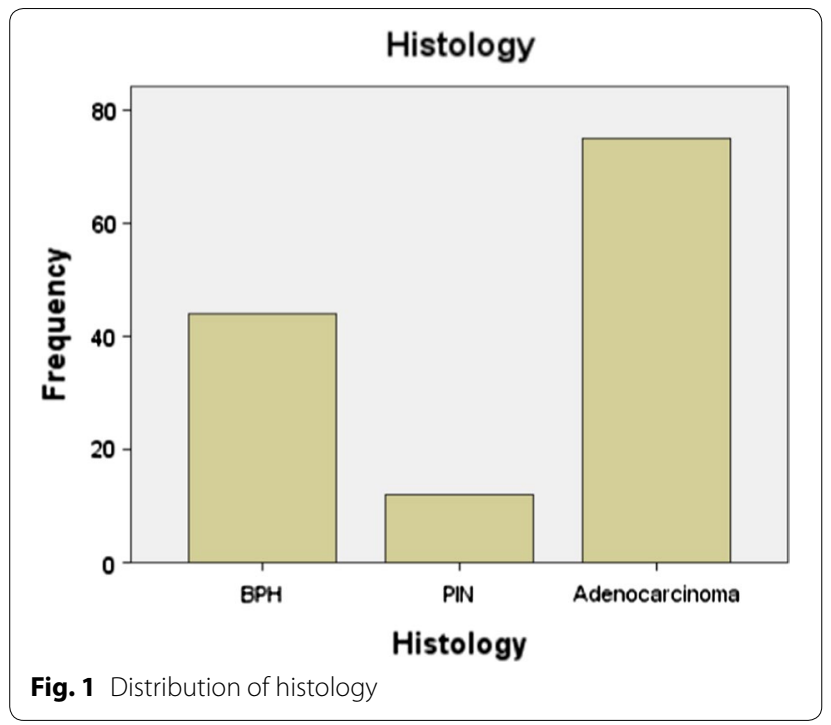

The commonest singular digital rectal examination finding was a hard nodular prostate $(22.9 \%)$, while the least was lobar asymmetry $(0.8 \%)$. Out of the 30 men with a hard nodular prostate, $6(20 \%)$ had nodular hyperplasia, $2(6.7 \%)$ had prostate intra-epithelial neoplasia, and $22(73.3 \%)$ were adenocarcinoma. Table 2 shows the relationship between DRE findings and histology.

Of the 131 men, 64 had a DRE finding of a hard nodular prostate either singularly or in combination out of which 51 (79.7\%) had adenocarcinoma (see Table 2). A hard nodular prostate was the most common DRE finding predicting the risk of adenocarcinoma. A suspicious nodule was the next most common finding, occurring in 26 men out of whom 6 (23.1\%) had adenocarcinoma. The least was lobar asymmetry with a PPV of $0 \%$.

Over all, there was a statistically significant correlation $(P=0.005)$ between DRE findings and histology and between PSA and histology $(P=0.000)$. Of the 3 men whose PSA was between 0 and $4 \mathrm{ng} / \mathrm{ml}, 1$ (33.3\%) had histological adenocarcinoma, whereas $5(10.2 \%)$ of those whose PSA was above $50 \mathrm{ng} / \mathrm{ml}$ were histologically nodular hyperplasia. The mean size of the prostate was $101.2 \mathrm{~g}$, standard deviation 92.11783, maximum $648 \mathrm{~g}$ and minimum $13.6 \mathrm{~g}$. There was a statistically significant correlation $(P=0.021)$ between the size of the prostate and PSA value.

\section{Discussion}

Insufficient data exist on prostate cancer in the West African subregion in spite of the huge burden of the disease. This made it difficult to establish guidelines for its management. In Nigeria, available data are from the
Table 2 The relationship between DRE finding and histological adenocarcinoma (PPV)

\begin{tabular}{|c|c|c|c|c|}
\hline \multirow[t]{2}{*}{ DRE finding } & \multicolumn{3}{|c|}{ Histology } & \multirow[t]{2}{*}{ Total } \\
\hline & BPH & PIN & Adenocarcinoma & \\
\hline $\mathrm{A}, \mathrm{H}$ & 0 & 0 & $(100 \%) 2$ & 2 \\
\hline$A, I$ & 0 & 1 & (50\%) 1 & 2 \\
\hline$A, S$ & 2 & 0 & $(33.3 \%) 1$ & 3 \\
\hline $\mathrm{H}$ & 6 & 2 & (73.3) 22 & 30 \\
\hline । & 5 & 1 & $(50 \%) 6$ & 12 \\
\hline $1, S$ & 0 & 2 & $(33.3 \%) 1$ & 3 \\
\hline$A$ & 1 & 0 & (0\%) 0 & 1 \\
\hline $\mathrm{A}, \mathrm{H}$ & 0 & 0 & (100\%) 1 & 1 \\
\hline $\mathrm{O}$ & 9 & 1 & $(23.1 \%) 3$ & 13 \\
\hline $\mathrm{O}, \mathrm{A}$ & 0 & 0 & (100\%) 1 & 1 \\
\hline $\mathrm{O}, \mathrm{A}, \mathrm{H}$ & 1 & 0 & $(75 \%) 3$ & 4 \\
\hline $\mathrm{O}, \mathrm{A}, \mathrm{H}$ & 1 & 0 & (80\%) 4 & 5 \\
\hline $\mathrm{O}, \mathrm{H}$ & 4 & 0 & (83\%) 20 & 24 \\
\hline $\mathrm{O}, \mathrm{H}, \mathrm{I}$ & 0 & 0 & (100\%) 1 & 1 \\
\hline $\mathrm{O}, \mathrm{H}, \mathrm{S}$ & 0 & 0 & (100\%) 1 & 1 \\
\hline $0,1, S$ & 0 & 0 & (100\%) 2 & 2 \\
\hline $\mathrm{O}, \mathrm{A}$ & 0 & 0 & (100\%) 1 & 1 \\
\hline $\mathrm{O}, \mathrm{S}$ & 0 & 1 & (50\%) 1 & 2 \\
\hline 0,1 & 0 & 0 & $(100 \%) 1$ & 1 \\
\hline S & 16 & 4 & $(23.1 \%) 6$ & 26 \\
\hline Total & 44 & 12 & (57.3\%) 75 & 131 \\
\hline
\end{tabular}

$H$ hard nodular, $S$ suspicious nodule, $O$ obliterated median groove, $A$ lobar asymmetry, I indurations

urban centers and are mostly on incidence and prevalence of the disease $[8,9]$.

DRE is a veritable tool in the diagnosis of carcinoma of the prostate. The features on DRE which may arouse the suspicion of carcinoma of the prostate are an enlarged prostate, suspicious nodule, hard nodular prostate, lobar asymmetry, the presence of indurations and obliteration of the median groove. The sensitivity of DRE is poor and is estimated to be $53-59 \%$, while the specificity is 83-94\%. The positive predictive value has been placed at $18-20 \%$. Data available indicate that the PSA level is as effective as or more effective than DRE for detection of prostate cancer [10]. This explains the stronger significant correlation between PSA and histology $(P=0.000)$ than between DRE findings and histology $(P=0.005)$ in this study. The high PPV of 66.5 documented here for DRE can be explained by the phenomenon of late presentation in this environment at a time the features of the disease are usually obvious on DRE.

The various findings which sum up to constitute abnormal DRE findings were handed down decades ago, and their value does not seem to have been validated in our region. In this study, a hard nodular prostate, with a 
positive predictive value (PPV) of 73 (Table 2), appears to be the only independent finding that strongly predicts the risk of adenocarcinoma. This PPV is lower than the 81 documented for DRE by Walsh et al. [6]. Apart from a hard nodular feel, the others apparently need to be evaluated in association with other variants or combined with a PSA assay to enable a decision to biopsy in order to minimize negative biopsies. This assertion can be buttressed with the PPV of a suspicious nodule, obliterated median groove and lobar asymmetry (Table 2).

A suspicious nodule in the prostate may result from previous biopsy, prostatitis, benign prostatic hyperplasia, prostatic calculi and malignancies of the prostate. Of the 26 men who had a suspicious nodule in the prostate as a sole finding in this study, only 6 (23.1\%) had adenocarcinoma giving a PPV of 23.1 despite the additional targeted biopsies. In the work of Lopes et al. [11] out of 34 men with suspicious nodules, 25 (74\%) were, however, adenocarcinoma, a sharp contrast to our finding. This may be a regional, racial or interobserver difference probably related to the differences in prevalence of the above-mentioned cofounders.

Lobar asymmetry was a sole abnormality in one $(0.8 \%)$ of the participants of which the histology was nodular hyperplasia giving a PPV of $0 \%$. Though this figure is too low to enable a fair conclusion, it is doubtful whether lobar asymmetry occurring alone should be an indication for prostate biopsy in the presence of a normal PSA. This opinion is similar to that of Hansen et al. [12] who documented a PPV of 25 for lobar asymmetry and therefore concluded that this finding on DRE is not associated with significant increase in cancer detection when compared to normal prostate. Finding of lobar asymmetry on DRE has a high potential for subjectivity and needs to be verified by trans- rectal ultrasonography.

According to Thompson et al. [13], there is no absolute lower value of PSA below which there is no risk of prostate cancer. They also documented that PSA is a marker whose values reflect a continuum of risk for prostate cancer. This is corroborated by this study in which $33.3 \%$ of men with PSA between 0 and $4 \mathrm{ng} / \mathrm{ml}$ had histologically proven adenocarcinoma while $10.2 \%$ of them with a PSA above $50 \mathrm{ng} / \mathrm{ml}$ had histological nodular hyperplasia.

Increasing age has been known to be a risk factor for carcinoma of the prostate [14] with a peak incidence often documented to be in the seventh decade of life [15, 16].This is in contrast to this study in which the peak incidence was in the 8th decade of life. This difference may be accounted for by late presentation which is common in this low resource setting $[17,18]$ compared to the developed world where most are currently commonly screen detected at an early stage and age, raising the fear of over diagnosis and over treatment $[6,19,20]$. This late presentation is also reflected in the high Gleason score in this study, indicating that most of these men presented with advanced disease. This is presently the norm in SubSaharan Africa [21, 22]. The peak age incidence is, however, similar to that documented by Albasri et al. [23] and Obiorah et al. [24].

The limitation of this study is in the number of participants which is low considering the burden of the disease in this region. Secondly, digitally guided transrectal biopsy technique was used though this was premised on the fact that DRE was being studied. The participants were more of a cohort of men with late disease, implying that this study cannot be generalized to early prostate cancer. Hopefully, phase 2 of this study may resolve these limitations though this study has been able to throw some light on the value of DRE and its variants in our environment.

\section{Conclusion}

DRE remains a veritable asset to the urologist in assessing men suspected of harboring prostate malignancy. Apart from a hard nodular finding with a PPV of 73.3\%, the other variants of abnormal DRE findings such as lobar asymmetry, suspicious nodule and obliterated median groove do not significantly predict cancer to stand individually as indication for biopsy in our environment. They need to be evaluated in the context of other abnormalities and PSA value.

\section{Abbreviations}

DRE: digital rectal examination; PSA: prostate specific examination; PPV: positive predictive value; LUTS: Iower urinary tract symptoms; $\mathrm{BPH}$ : benign prostatic hyperplasia.

\section{Acknowledgements}

None.

\section{Authors' contribution}

El was involved in conception, drafting of proposal and proforma, collection of data and data analysis and writing of the manuscript. GOA contributed to data collection and analysis and intellectual review of the manuscript. UA contributed to data collection and analysis. All authors read and approved the final manuscript.

Funding

This study was funded by the authors. No external funding was received.

\section{Availability of data and materials}

The data underlying the results of the study are available as part of the article. Additional source data are not required.

\section{Ethics approval and consent to participate}

The proposal for this study was submitted to the Ethic committee of the Irrua Specialist Teaching Hospital in September 2015. Approval was conveyed via the letter HREC. NO:ISTH/HREC/2015/OCTOBER/012. However, for logistic reasons, the work could not start until April 2016, having discussed this with the committee. Irrua Specialist Teaching Hospital is a Federal Teaching Hospital affiliated to Ambrose Alli University Ekpoma. Consent for participation was obtained from all the patients. All the authors have read the manuscript and agreed that it should be published. 


\section{Consent for publication}

All patients included in this research gave written informed consent to publish the data contained within this study.

\section{Competing interest}

The authors declare that they have no competing interests.

\section{Author details}

${ }^{1}$ Department of Surgery, Ambrose Alli University, Ekpoma, Nigeria. ${ }^{2}$ Department of Surgery, Federal Medical Center, Umuahia, Nigeria. ${ }^{3}$ Department of Surgery, Irrua Teaching Hospital, Irrua, Nigeria.

Received: 17 October 2019 Accepted: 20 November 2019

Published online: 08 January 2020

\section{References}

1. Ojewola RW, Jeje EA, Tijani KH, Ogunjimi MA, Anunobi CC (2013) Clinicopathological correlation of digital rectal examination findings amongst Nigerian men with prostate cancer disease: a prospective study of 236 cases. Niger J Surg 19(1):26-31. https://doi.org/10.4103/1117-6806.11150 6

2. Hoogen Dam A, Bumtinxa F, de Vet HCW (1999) The diagnostic value of digital rectal examination in primary care screening for prostate cancer: a meta analysis. Fam Pract 16:621-626

3. Majeed A, Babb P, Jones J, Quinn M (2000) Trends in prostate cancer incidence mortality and survival in England and Wales 1971-1998. BJU Int 85(9):1058-1062

4. Catalona WJ, Richie JP, Ahmann FR, Hudson MA, Scardino PT, Flanigan RC et al (1994) Comparison of digital rectal examination and serum prostate specific antigen in the early detection of prostate cancer. Result of multicentre clinical trial of 6,630 men. J Urol 15:1283-1290

5. Cupp MR, Oesterting JE (1993) Prostate specific antigen, digital rectal examination and trans rectal ultrasonography. Their role in diagnosing early prostate cancer. Mayo Clin Proc 68(3):297-306

6. Walsh AL, Considine SW, Thomas AZ, Lynch TH, Manecksha RP (2014) Digital rectal examination in primary care is important for early detection of prostate cancer: a retrospective cohort analysis study. Br J Gen Pract 64(629):783-787. https://doi.org/10.3399/bjgp14×682861

7. Tombal B (2012) Toward the end of blind prostate biopsies? Eur Urol 62(6):997-998

8. Ezenwa E, Tijani K, Jeje A, Ogunjimi A, Ojewola R (2012) Prevalence of prostate cancer among nigerians with intermediate total prostate specific antigen levels (0-4 ng/ml): experience at Lagos University Teaching Hospital. Int J Urol 9:3

9. Eke N, Sapira MK (2002) Prostate cancer in Port Harcourt, Nigeria: features and outcome. Niger J Surg 4:34-44
10. Irekpita E, Owobu C, Aigbe E, Obasikene G, Igbe A (2014) Assessment of DRE and PSA as diagnostic and screening tools for carcinoma of the prostate in rural Nigeria. East Cent Afr J Surg 19(3):53

11. Lopes PM, Sepúlveda L, Ramos R, Sousa P (2015) The role of transrectal ultrasound in the diagnosis of prostate cancer: new contributions. Radiol Bras 48(1):7-11. https://doi.org/10.1590/0100-3984.2013.0010

12. Hansen JG, Dalkin BL, Haris CH, Johnson CS, Ahmann FR (1997) Prostatic asymmetry as a risk factor for prostatic carcinoma: serial prostate specific antigen monitoring and cancer detection. J Urol 157(4):1340-1343

13. Thompson IM, Ankerst DP, Chi C et al (2005) Operating characteristics of prostate-specific antigen in men with an initial PSA level of $3.0 \mathrm{ng} / \mathrm{mL}$ or lower. JAMA 294(1):66-70. https://doi.org/10.1001/jama.294.1.66

14. America Cancer Society facts and figures, Atlanta, America Cancer Society 2008 (cross ref)

15. Nwafor CC, Keshinro OS, Abudu EK (2015) A histopathological study of prostate lesions in Lagos, Nigeria: a private practice experience. Niger Med J 56(5):338-343. https://doi.org/10.4103/0300-1652.170388

16. Aligbe JU, Forae GD (2013) Prostatic tumours among Nigerian males: a private practice experience in Benin-City, South-South, Nigeria. Niger Postgrad Med J 20(3):193-196

17. Hoffman RM, Gilliland FD, Eley JW, Harlan LC, Stephenson RA, Stanford JL et al (2001) Racial and ethnic differences in advanced-stage prostate cancer: the Prostate Cancer Outcomes Study. J Natl Cancer Inst 93(5):88-95

18. Yawe KT, Tahir MB, Nggada HA (2006) Prostate cancer in Maiduguri. West Afr J Med 25(4):298-300

19. Ohori M, Scardino PT (1994) Early detection of prostate cancer: the nature of cancers detected with current diagnostic tests. Semin Oncol 21(5):522-526

20. Ammani A, Janane A, Bouzide B, Dehayni Y, Lezrek M, Ghadouane M et al (2016) Accuracy of the contemporary Epstein criteria to predict insignificant prostate cancer in North African Man. Afr J Urol 22(3):168-174

21. Olapade-Olaopa EO, Obamuyide HA, Yisa GT (2008) Management of advanced prostate cancer in Africa. Can J Urol 15(1):3890-3898

22. Osegbe DN (1997) Prostate cancer in Nigerians: facts and non facts. J Urol 157(4):1340-1343

23. Albasri A, El-Siddig A, Hussainy A, Mahrous M, Alhosaini AA, Alhujaily A (2014) Histopathologic characterization of prostate diseases in Madinah, Saudi Arabia. Asian Pac J Cancer Prev 15(10):4175-4179

24. Obiorah CC, Nwosu SO (2011) A histopathological study of carcinoma of the prostate in Port Harcourt, Nigeria. Niger J Clin Pract 14(3):363-367. https://doi.org/10.4103/1119-3077.86785

\section{Publisher's Note}

Springer Nature remains neutral with regard to jurisdictional claims in published maps and institutional affiliations.

\section{Submit your manuscript to a SpringerOpen ${ }^{\circ}$ journal and benefit from:}

- Convenient online submission

- Rigorous peer review

- Open access: articles freely available online

- High visibility within the field

Retaining the copyright to your article

Submit your next manuscript at springeropen.com 